\title{
MULTITUDINOUS HEART: UMA ANÁLISE DA TRADUÇÃO DE POEMAS DRUMMONDIANOS PARA A LÍNGUA INGLESA
}

\author{
MULTITUDINOUS HEART: AN ANALYSIS OF DRUMMOND'S POETRY INTO \\ THE ENGLISH LANGUAGE
}

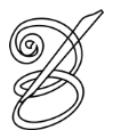 \\ Mariane Pereira ROCHA* \\ Instituto Federal Sul-Rio-Grandense, Brasil \\ Aulus Mandagará MARTINS*** \\ Universidade Federal de Pelotas, Brasil
}

\begin{abstract}
Resumo: Neste ensaio, são analisados três poemas de Carlos Drummond de Andrade traduzidos para língua inglesa por Richard Zenith e publicados na coletânea Multitudinous heart: selected poems by Carlos Drummond de Andrade em Nova York, no ano de 2015, pela editora Farrar, Straus and Giroux. O objetivo desta análise é, reconhecendo o processo tradutório como um fenômeno intertextual, entender o diálogo entre a obra original e a obra traduzida, analisando como o tradutor soluciona problemas próprios da tradução de poesia, como a correspondência de ritmo e sons e a correspondência semântica entre sistemas linguísticos tão diferentes quanto o inglês e o português. Para elaborar essa reflexão, além dos poemas selecionados, também são utilizadas traduções realizadas anteriormente por outros tradutores, com o intuito de comparar e contrastar diferentes abordagens do texto poético e suas soluções linguísticas. A reflexão teórica leva em consideração as discussões de Gérard Genette (2005) e Walter Benjamin (2008) sobre a tradução enquanto fenômeno intertextual e o papel do tradutor, de Haroldo Campos (2011) para a problematização da tradução literária, bem como de Tania Carvalhal (2000) para se pensar na recepção da tradução. A partir das análises, foi possível depreender características singulares no projeto tradutório de Zenith, o qual faz escolhas e encontra soluções tradutórias que ainda não tinham aparecido em traduções anteriores da poesia drummondiana. Assim, encontra-se em Zenith uma atualização da poesia de Drummond em língua inglesa, em um movimento que busca dialogar com o público leitor, bem como preservar o ritmo e as rimas da poesia drummondiana. Traça-se, então, hipóteses e delimita-se tendências nos poemas analisados a fim de iniciar o debate sobre essa tradução ainda recente de poemas de Drummond traduzidos para a língua inglesa.
\end{abstract}

Palavras-chave: Tradução literária. Tradução de poesia. Poesia brasileira. Carlos Drummond de Andrade. Richard Zenith.

\begin{abstract}
In this essay, three poems by Carlos Drummond de Andrade translated into English are analyzed. They were translated by Richard Zenith and published in New York in 2015, by Farrar, Straus and Giroux publisher into the collection Multitudinous heart: selected poems by Carlos Drummond de Andrade (2015). The purpose of this analysis is, recognizing the process as an intertextual phenomenon, to analyze how the translator solves problems of poetry translation, such as correspondence of rhythm and sounds and the semantic correspondence between linguistic systems as different as English and Portuguese as well as to understand the dialogue between the different works. In order to elaborate this reflection, in addition to the selected poems, previous translations by other translators are also used, in order to compare and contrast different approaches of the poetic text and its linguistic solutions. The theoretical reflection considers the discussions of Gérard Genette (2005) and Walter Benjamin (2008) about the translation as an intertextual practice and the translator role, of Haroldo Campos (2011) to problematize the literary translation, as well as Tania Carvalhal (2000) to think about the translation reception. From the analyzes, it was possible to understand singular characteristics in Zenith's translation project, which makes choices and finds translation solutions that had not yet appeared in previous translations of drummondian poetry. Thus, in Zenith it was found an update of Drummond's poetry in English, in a movement that seeks to dialogue with the reading public, as well as to preserve the rhythm and rhymes of Drummond poetry.
\end{abstract}


Hypotheses are then traced and tendencies delimited in the analyzed poems in order to start the debate on this still recent translation of Drummond's poems translated into the English language.

Keywords: Literary translation. Poetry translation. Brazilian poetry. Carlos Drummond de Andrade. Richard Zenith.

RECEBIDO EM: 10 de maio de 2019

ACEITO EM: 10 de setembro de 2019

PUBLICADO EM: janeiro 2020 


\section{Introdução}

obra poética de Carlos Drummond de Andrade possui importância significativa na 1 consolidação do cânone da literatura brasileira. Trinta anos após a morte do poeta, 1 ainda surgem novas edições de seus livros, com prefácio e posfácio de grandes nomes da crítica literária brasileira, bem como publicações inéditas de cartas e diários pessoais do escritor mineiro. Além disso, sua poesia se manifesta também nas novas produções poéticas, seja através de referências explícitas aos poemas de Drummond, seja por determinada dicção drummondiana que se faz presente na construção de um imaginário lírico brasileiro e se manifesta na produção contemporânea de poetas como Ana Martins Marques e Carlito Azevedo.

É nesse contexto que se torna importante observar também como a produção drummondiana se estende para fora do Brasil. Santiago (2007), em introdução à Poesia completa de Drummond, reflete sobre a capacidade dessa poesia, com traços tão locais, se apresentar ao mesmo tempo universal:

como uma poesia que tematiza com insistência e sabedoria a vida provinciana na Itabira do Mato Dentro pode oferecer-se de maneira tão cosmopolita ao seu leitor, passando-lhe a impressão de que o poeta é un homme du monde, nascido no século de Voltaire e Rousseau? [...] Que força é esta que leva o poeta a levantar os olhos do solo natal e tentar entender amorosamente outras nações e diferentes povos? (SANTIAGO, 2007, p. 7)

No que diz respeito às traduções da poesia drummondiana para a língua inglesa, John Gledson (2003) explicita que, até o começo do século XXI, havia apenas três publicações dos poemas traduzidos em livros. Nesse sentido, o autor afirma que:

\footnotetext{
há pouca tradição de tradução literária do português para o inglês, e, como é bem sabido, a tradução (e mais ainda da poesia) não é atividade que compense em termos financeiros. Os tradutores são às vezes mais amadores do que profissionais - e autores da envergadura de Machado de Assis, Graciliano Ramos, e (o que é mais compreensível) de Guimarães Rosa já sofreram bastante em suas mãos (GLEDSON, 2003, p. 283).
}

É importante mencionar, contudo, que em um cenário de produção literária vasta, como a encontrada a partir da segunda metade do século XX, três publicações é um número significativo, visto que escritores importantes para a consolidação da poesia brasileira nunca chegaram a ser traduzidos para o inglês. Além disso, dentre as traduções mencionadas por Gledson, encontramos nomes importantes da produção poética e da tradução, como Elizabeth Bishop. 
Assim, neste ensaio, serão analisados três poemas de Drummond em língua inglesa que se encontram em Multitudinous heart: selected poems by Carlos Drummond de Andrade, obra publicada em Nova York, pela editora Farrar, Straus and Giroux no ano de 2015. Todos os poemas desse livro foram traduzidos por Richard Zenith, nome já consagrado pela tradução para língua inglesa de poetas de língua portuguesa, sejam eles brasileiros ou portugueses, como Fernando Pessoa, Luís de Camões, João Cabral de Mello Neto e Sophia de Mello Breyner Andresen.

O objetivo desta análise é, reconhecendo o processo tradutório como um fenômeno intertextual, entender o diálogo entre a obra original e a obra traduzida, atentando para fatores, como o contexto de recepção, e analisando como o tradutor soluciona problemas próprios da tradução de poesia, como a correspondência de ritmo e sons e a correspondência semântica entre sistemas linguísticos tão diferentes quanto o inglês e o português. Para elaborar essa reflexão, além dos poemas selecionados, também serão utilizadas traduções realizadas anteriormente por outros tradutores, com o intuito de comparar e contrastar diferentes abordagens do texto poético e suas soluções linguísticas. A reflexão teórica levará em

112 consideração as discussões de Gérard Genette (2005) e Walter Benjamin (2008) sobre a tradução enquanto fenômeno intertextual e o papel do tradutor, de Haroldo Campos (2011) para a problematização da tradução literária, bem como de Tania Carvalhal (2000) para pensar na recepção da tradução.

\section{Traduzir, criar, poetizar}

De acordo com Genette (2005), toda obra que deriva de uma obra anterior, seja por imitação, seja por transformação, é um hipertexto, ou, como o autor definiu, um palimpsesto. É nesse sentido que a tradução pode ser considerada uma prática intertextual, visto que invariavelmente advém de uma obra anterior, normalmente chamada de "original". Se o texto base é o "original", consequentemente o texto traduzido é considerado um texto menor, frequentemente classificado como "cópia", "imitação" ou mera reprodução do texto base. Ainda de acordo com o autor, esse é um fenômeno comum entre todas as práticas intertextuais: “dessa literatura de segunda mão, que se escreve através da leitura, o lugar e a ação no campo literário geralmente, e lamentavelmente, não são reconhecidos.” (GENETTE, 2005, p. 7).

Percebemos, então, que é essa aproximação inevitável com o texto base que causa problemas à percepção da tradução. É ela que, frequentemente, leva a uma exigência de "fidelidade" que é impossível de ser alcançada, concedendo às traduções essa injusta reputação 
de gênero menor. Benjamin (2008) refletiu sobre essa impossibilidade da tradução de reproduzir o texto base:

nenhum dado do conhecimento pode ser ou ter pretensões a ser objetivo quando se contenta em reproduzir o real, e do mesmo modo também nenhuma tradução será viável se aspirar essencialmente ser uma reprodução parecida ou semelhante ao original. Isso porque o original se modifica necessariamente na sua "sobrevivência" [...]. Mesmo para as palavras já definitivamente sepultadas num determinado texto existe um amadurecimento póstumo (BENJAMIN, 2008, p. 30).

Nesse mesmo sentido, Genette afirmou que "nenhuma tradução pode ser absolutamente fiel e todo ato de traduzir altera o sentido do texto traduzido" (GENETTE, 2005, p. 65).

Genette reconhece ainda que a tradução interlingual, ou seja, de uma língua para outra, ocupa uma posição de maior valorização em relação às outras formas de transposição já que, segundo ele, sua "importância literária não é muito contestável, seja porque é necessário traduzir bem as obras-primas, seja porque algumas traduções são elas próprias obras-primas" (GENETTE, 2005, p. 65). De fato, é inegável que o acesso a outros sistemas literários, que somente a tradução permite, perpassou toda a construção de conhecimento dos últimos séculos e, sem ela, nossos acervos de leitura seriam significativamente menores. Nessa perspectiva, Carvalhal (2000) reflete que hoje já não é mais possível deixar de reconhecer

\begin{abstract}
que as traduções são elementos importantes nos processos de circulação literária e que devem ser estudadas em si mesmas e nas diferentes formas de sua contribuição, como concretização possível de outros textos e de outras culturas. Trata-se, sem dúvidas, de um recurso indispensável à escrita da história literária, pois que a análise das traduções, no seu conjunto, possibilita acompanhar a evolução das formas e dos efeitos, dos gêneros e do gosto, através da penetração tardia de ideias, de estilos e de atitudes críticas que não são as nossas. (CARVALHAL, 2000, p. 87)
\end{abstract}

No que diz respeito à tradução de poesia, Genette (2005) relata que nomes importantes da poesia como Paul Valéry e Stéphane Mallarmé acreditavam haver na poesia um fator de "intraduzibilidade", devido à indissolubilidade entre som e sentido, que tornaria a tradução poética para outras línguas inviável. Certamente, a tradução de poesia parece ocupar um lugar significativo nas discussões sobre os impasses da tradução. Tradutores, como Ivan Junqueira (2012), apontam os desafios do ato de traduzir, entre eles, o domínio dos dois idiomas e o conhecimento das diferentes culturas envolvidas e a exigência pela fidelidade. Para ele, a tradução da poesia apresenta, além de tudo isso, desafios específicos do gênero, "como os do ritmo, da estrutura sintático-verbal, dos esquemas métricos e rímicos, da linguagem metalógica, 
do jogo de imagens e metáforas e de todos os outros elementos que constituem a retórica poética" (JUNQUEIRA, 2012, p. 9).

Genette, porém, explica que existem dificuldades em todas as traduções literárias, em prosa ou em poesia. Ele enfatiza que:

se quiséssemos precisar os termos da armadilha para tradutores, eu os descreveria como se segue. Do lado da "arte da linguagem", tudo está dito desde Valéry e Blanchot: a criação literária é sempre parcialmente inseparável da língua em que ela se exerce. Do lado da "língua natural", tudo está dito desde a observação de Jean Paulhan sobre "a ilusão dos exploradores" diante do enorme contingente de clichês, isto é, catacreses, ou figuras que passaram ao uso nas línguas, "primitivas" ou não (GENETTE, 2005, p. 67).

Benjamin, entretanto, vai refletir que o desafio do trabalho linguístico é muito mais marcado na tarefa do tradutor do que na do escritor do texto base, uma vez que

ela [a tarefa do tradutor] consiste em encontrar na língua em que se está traduzindo aquela intenção por onde o eco do original pode ser ressuscitado. Trata-se aqui de uma característica da tradução que a distingue claramente da obra poética, pois que a intenção desta não visa a língua por si mesma e na sua totalidade, pretendendo apenas obter diretamente determinadas relações linguísticas. Porém, ao contrário do que acontece com a poesia original, a tradução não se encontra situada no próprio centro da floresta da língua, mas sim fora desta, e sem entrar nela a tradução invoca-a para aquele mesmo e único sítio onde o eco, através da própria ressonância da obra, pode transmitir-se a uma língua estranha (BENJAMIN, 2008, p. 36).

Nesse mesmo sentido, Haroldo de Campos (2011) discute que são os problemas próprios da tradução literária que possibilitam que o trabalho do tradutor seja criativo e que funcione como uma recriação do texto original. Para ele,

tradução de textos criativos será sempre recriação, ou criação paralela, autônoma porém recíproca. Quando mais inçado de dificuldades esse texto, mais recriável, mais sedutor enquanto possibilidade aberta de recriação. Numa tradução dessa natureza, não se traduz apenas o significado, traduz-se o próprio signo, ou seja, sua fisicalidade, sua materialidade mesma (propriedades sonoras, de imagética visual, enfim tudo aquilo que forma, segundo Charles Morris, a iconicidade do signo estético, entendido por "signo icônico" aquele "que é de certa maneira similar àquilo que ele denota"). $\mathrm{O}$ significado, o parâmetro semântico, será apenas e tão-somente a baliza demarcatória do lugar da empresa recriadora. (CAMPOS, 2011, p. 34)

Tal entendimento de tradução, enquanto recriação, será utilizado nesta análise, visto que se espera entender os mecanismos de língua que o tradutor utiliza e suas soluções para criar correspondências sintáticas, sonoras e semânticas nos diferentes sistemas linguísticos. Assim, não deixaremos de levar em conta os textos originais para as análises, mas os abordaremos em uma perspectiva comparada, na tentativa de apreensão do processo tradutório e, ainda, de 
aprofundar o entendimento de características do lirismo drummondiano em diferenças sistemas literários.

\title{
2 A estranha ideia de família
}

Drummond escreveu durante diferentes décadas, portanto, sua produção poética, além de vasta, perpassa diferentes períodos históricos. Encontramos um poeta de sete faces, que se insere no modernismo com humor e crítica em Alguma poesia (1930), que discute os problemas sociais de um tempo através de uma poesia socialmente ativa, como é possível perceber em Sentimento do mundo (1940) e A rosa do povo (1945), que reflete metafisicamente sobre o mundo, como em Claro Enigma (1950) e, finalmente, que busca no memorialismo um reencontro com o passado, a partir da triologia Boitempo $(1968 ; 1973 ; 1979)$. Todas essas faces drummondianas são perpassadas por um olhar pessoal do poeta que utiliza, frequentemente, o verso livre, uma sintaxe complexa e uma subjetividade característica. Para Santiago,

\begin{abstract}
nos poemas de Carlos Drummond de Andrade, os grandes acontecimentos públicos do século são expressos através duma atormentada, galhofeira ou benévola autoanálise. A esta se acopla uma reflexão poética de ordem pessoal e transferível sobre a vivência do cidadão brasileiro e do intelectual cosmopolita em tempos que podem ser trágicos, dramáticos, nostálgicos, pessimistas ou alegres. Experiência privada e fatos públicos nacionais e estrangeiros, em correlação e sistema de troca estranháveis, compõem a textura das sucessíveis coletâneas de poemas publicadas entre 1930 e 1996 (SANTIAGO, 2007, p. 4).
\end{abstract}

Entre as tantas temáticas desenvolvidas na poesia drummondiana, a temática familiar é recorrente e retorna em diferentes estágios de sua poesia, sendo trabalhada de forma dialética ao longo da trajetória lírica do poeta. O poema Viagem na família, do livro A rosa do povo (1945), é um dos mais representativos desse sentimento duplo e da dificuldade que o eu-lírico drummondiano apresenta ao trabalhar a memória familiar e, portanto, faz sentido que ele tenha sido selecionado para compor a coletânea de poemas que aqui será analisada.

$\mathrm{Na}$ tradução de Richard Zenith, ele utiliza o título Journey through the family, que parece ser capaz de captar a ideia expressa ao longo do poema: a jornada que o eu-lírico realiza através das memórias da família, levado pela lembrança do pai. Em traduções anteriores, encontramos outras opções de títulos, como Travelling in the family, de Elizabeth Bishop. "travel", ainda que seja a tradução literal de "viagem", é informal e apresenta uma ideia de passeio, de férias, turismo. "Journey", por sua vez, expressa a subjetividade que Drummond atribuiu à viagem que realiza junto à lembrança de seu pai já falecido. 
$\mathrm{Na}$ segunda estrofe do poema, vamos perceber que Drummond, em um movimento modernista, opta por um padrão métrico variado, com versos de 6,7 e 8 sílabas poéticas. Zenith acompanha esse padrão, embora não repita o mesmo tipo de verso para cada uma das linhas. Vejamos abaixo:

Longamente caminhamos

We walked for a long time.

Aqui havia uma casa.

Here there was a house.

A montanha era maior.

The mountain was taller back then.

Tantos mortos amontoados,

All the people who've died,

o tempo roendo os mortos.

time gnawing the dead.

E nas casas em ruína

desprezo frio, umidade.

Cold damp and disdain

in the ruined houses.

Porém nada dizia.

But he didn't say anything (ZENITH, 2015, v. 9-16)

A correspondência semântica é adequada, embora notemos que no quarto verso a imagem poética construída em "Tantos mortos amontoados" se dissolve em "All the people who've died", literalmente, "todas as pessoas que morreram". Além disso, a repetição de "mortos" no quarto e no quinto verso, primeiramente amontoados e depois roídos pelo tempo, reforça a noção de deterioração do passado, importantíssima na lírica drummondiana. Tal noção não é enfatizada na tradução, visto que os "mortos" só aparecem no quinto verso, "the dead", já que no quarto verso houve um eufemismo em "people who've died" [pessoas que morreram].

Outro ponto significativo é a inversão sintática que Zenith faz. No inglês, adjetivos vêm normalmente antes do substantivo, ao contrário do que acontece no português. Zenith opta, entretanto, por inverter também a ordem dos versos, como observamos nos sexto e sétimo versos citados acima. Portanto "E nas casas em ruínas / desprezo frio, umidade" se torna "Cold damp and disdain / in the ruined houses". Esta inversão sintática rompe, de certa forma, com determinada expectativa que, no original, é criada a partir de "casas em ruínas". Na tradução, já é entregue na primeira leitura o que vai ser encontrado nas casas em ruínas. Além disso, percebemos que Zenith, ao inverter os adjetivos, acaba descrevendo a "umidade" (cold damp) como fria em vez do original "desprezo frio" (disdain), deixando de lado a brincadeira poética 
que Drummond realiza ao aproximar "frio" não do outro fenômeno da natureza (umidade), mas sim do desprezo, utilizando assim o significado figurado de frio: insensível, cruel, rude.

Nas estrofes finais do poema, o eu-lírico drummondiano assume um tom mais dramático e as memórias começam a se confundir com a realidade, dando um caráter ainda mais denso ao poema:

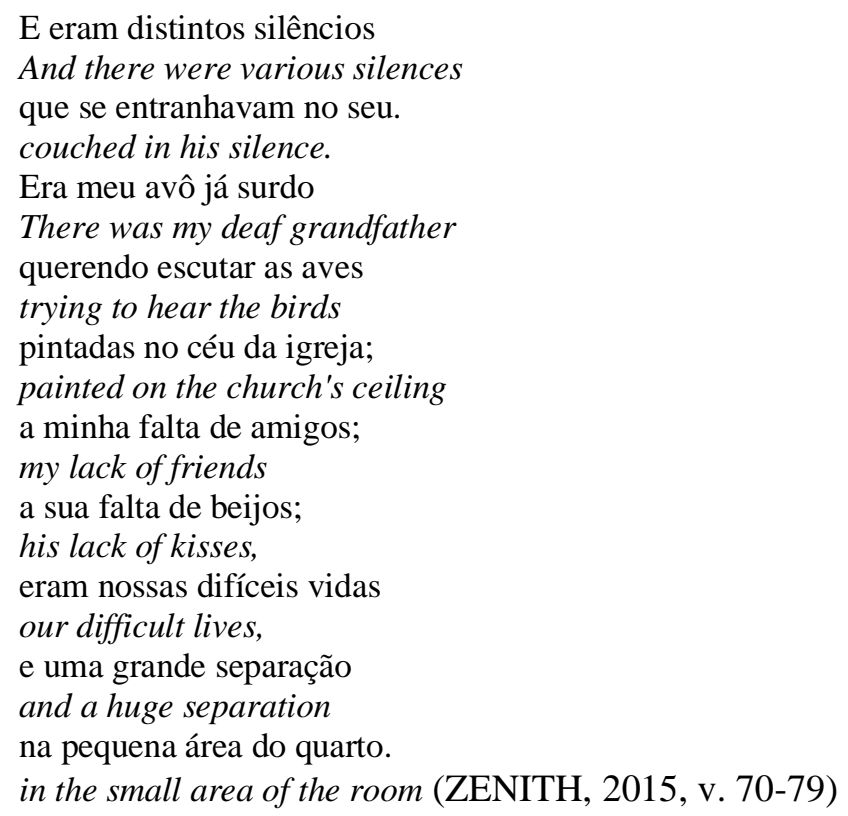

Mais uma vez, no entanto, notamos que a tradução parece "suavizar" alguns dos efeitos dramáticos que o original traz. Enquanto Drummond decide por "entranhavam", cujo significado literal é "introduzir nas entranhas", sentido bastante visceral, Zenith escolhe a palavra "couched", da qual a tradução seria "aninhado", causando um efeito de sentido mais sutil.

É possível perceber, ainda, que no original Drummond descreve quais eram os silêncios que estavam entranhados no silêncio de seu pai: "Era meu avô já surdo [...]/ (era) a minha falta de amigos / [...] (era) a sua falta de beijos / [...] eram nossas difíceis vidas". A tradução mais adequada para a construção desse "era", em inglês, seria "it was". Zenith, contudo, faz a opção por "there was", ou seja, "havia", assim o verso traduzido se transforma em "Havia meu avô surdo", não fazendo uma correspondência tão clara com os versos anteriores; dessa forma, a ligação de que esses eram os silêncios dos quais o eu-lírico se referia anteriormente não fica tão evidente na tradução.

Nos versos finais da estrofe citada, o tradutor faz uma oposição interessante entre "small" e "huge", quando Drummond utiliza "grande separação" e "pequena área do quarto". 
Essa opção parece ser mais coerente do que a utilizada por Bishop em sua tradução, na qual coloca "and a great separation /in the little space of the room", uma vez que "great" e "little" não são exatamente pares opostos, como "small" e "huge", já que ambos expressam claramente essa noção de espaço, que fica um tanto difusa no segundo par.

Assim, é possível afirmar que a tradução de Zenith, Journey in the family, preserva muito do ritmo e da estrutura do poema Viagem na família e, além disso, cria correspondências semânticas bastante próximas, mantendo, de forma geral, o sentido do texto original. Apesar disso, há certa dicção drummondiana que não está presente na versão de Zenith: ao realizar as inversões sintáticas e ao utilizar eufemismos, dando um tom mais sutil às palavras, a tradução não enfatiza a dramatização, o pessimismo e a violência que, em Drummond, recebem destaque.

\title{
3 Fique torto no seu canto
}

O poema Segredo do livro Brejo das almas (1934) é considerado pela crítica o primeiro poema metalinguístico de Drummond, no qual o poeta reflete sobre o fazer poético enquanto impossibilidade. Além disso, o pessimismo, característica frequentemente associada à poética

118 drummondiana, fica bastante evidente nesse poema. De acordo com Murilo Moura,

\begin{abstract}
a marca do poema na página já deixa ver muita coisa: quatro partes, com alguma regularidade, todas elas encerradas por uma negativa - "Não ame"; "Não diga nada"; "Não conte"; "Não peça". Digamos que o poema desenhe um eixo, uma espécie de espinha dorsal, composta justamente pelo acúmulo simétrico da palavra "não". O poema é radical em sua negatividade e nada parece escapar dela; seu tom peremptório, definitivo, parece ser extraído (numa forma de paródia) de discursos que se autoatribuem verdades inquestionáveis - religiosos, científicos, políticos, mas aqui invertidos, já que tudo é nulo ou nada tem validade (MOURA, 2010, p. 52-53).
\end{abstract}

$\mathrm{Na}$ tradução de Zenith, percebemos que ele mantém essa "espinha dorsal" ao qual Moura se refere, utilizando todas as negativas que Drummond fez uso, conforme podemos verificar abaixo:

\author{
Poetry can't be communicated \\ Stay knotted up in your corner. \\ Don't love. \\ I hear there's shooting \\ and we're within range. \\ Is it the revolution? Love? \\ Don't say a thing. \\ Everything's possible, only I'm impossible. \\ The sea's overflowing with fish.
}


There are men who walk on the sea.

as if on the street.

Don't tell.

\author{
Suppose an angel of fire \\ were to sweep the face of the earth \\ and the people being sacrificed \\ begged for mercy. \\ Don't beg (ZENITH, 2015, v. 1-17, grifo nosso)
}

É interessante notar, ainda, a escolha que o tradutor faz por utilizar a contração " $d o n$ ' $t$ " quando a opção mais óbvia seria "do not", que além de mais formal é também mais incisiva. O "don ' $t$ ", contudo, é mais utilizado na linguagem falada, dando assim, à tradução, um tom mais coloquial. Em contraste com outras traduções, como a de John Nist, que publicou o livro In the middle of the road em 1965, Zenith mostra consistência nesse aspecto, pois preserva o uso do “don't" ao longo dos versos, ao contrário de Nist que varia entre "do not" e "nothing" (say nothing/ beg nothing), podendo certa confusão no leitor, que já não é evidente qual o grau de formalidade do poema.

A primeira estrofe do poema drummondiano dialoga fortemente com toda sua obra poética: “A poesia é incomunicável. / Fique torto no seu canto. Não ame." (ANDRADE, 2015a, v. 1-2). O segundo verso da primeira estrofe remete à característica gauche drummondiana, já anunciada no poema que abre sua obra, o famoso Poema de sete faces:

Quando nasci, um anjo torto desses que vivem na sombra disse: Vai, Carlos! ser gauche na vida. (DRUMMOND, 2015a, v. 1-3).

De acordo com Afonso Romano Sant'anna (2002), a noção de gauche é central para o entendimento da poética de Drummond, uma vez que é um “dos tópicos fundamentais, senão o fundamental, a partir do qual se deve procurar uma interpretação totalizante de sua obra" (SANT’ANNA, 2002, p. 19). O autor ainda explica que

gauche é a palavra em que se cristalizou a essência da personalidade do poeta. Significa basicamente o indivíduo desajustado, marginalizado, à esquerda dos acontecimentos. [...] Caracteriza o gauche o contínuo desajustamento entre a sua realidade e a realidade exterior (SANTANNA, 2002, p. 19, grifos do autor).

No verso "Fique torto no seu canto." do poema Segredo tanto a palavra "torto" quanto a palavra "canto" expressam essa ideia de desajuste e de deslocamento, sendo palavras-chave para a compreensão do poema como um todo. Na tradução de Zenith, ele utiliza "Stay knotted up in your corner", cuja transcrição seria "Fique preso em seu canto", omitindo a referência ao 
“torto" e, consequentemente, ao "gauche". Esse tipo de omissão é recorrente em traduções, uma vez que por mais que o tradutor tenha grande conhecimento das duas línguas, para transpor para outra língua sutilezas como essa, é necessário ter aprofundamento da obra completa do escritor que se está traduzindo.

Percebemos que este movimento de deixar em segundo plano a característica gauche drummondiana já estava evidente na tradução que Zenith faz do próprio Poema de sete faces, na qual que ele omite o termo:

When I was born, one of those twisted angels who live in the shadows said:

“Carlos, get ready to be a misfit in life!” (ZENITH, 2015, v. 1-3, grifo nosso).

Embora "misfit", seja a tradução literal de "desajustado", "gauche" é uma palavra francesa e, neste caso, não precisaria obrigatoriamente ser traduzida, podendo ser mantida como no original, conforme Bishop faz em sua tradução:

Dada a importância do termo para a obra drummondiana, acreditamos que a tradução de Bishop, nesse sentido, tenha mais correspondência semântica com a lírica de Drummond. Outros aspectos da tradução de Bishop foram bastante comentados à época de seu lançamento, como a substituição do nome "Raimundo", na sexta estrofe, por "Eugene”:

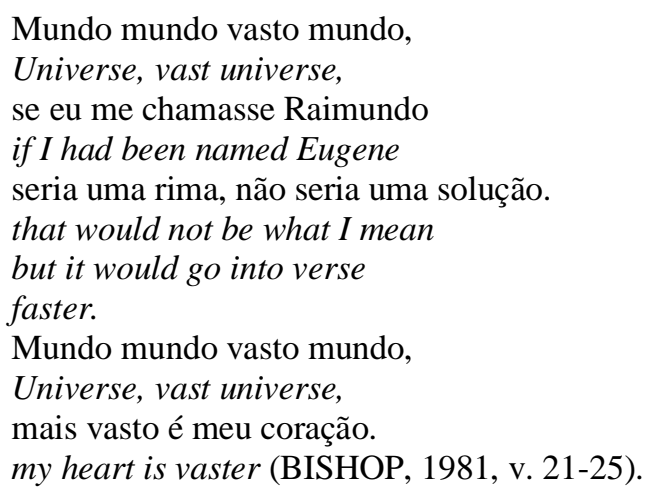

"Raimundo" é um nome comum no português que não é encontrado em inglês. Assim, ao substituí-lo por "Eugene", menos incomum aos falantes de língua inglesa, a tradutora 
aproxima o poema dos leitores. Zenith faz uma escolha bem próxima à de Bishop, optando também por substituir o nome:

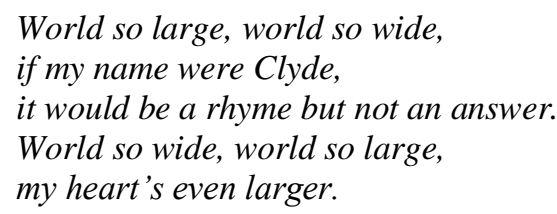

Observamos que a rima é importante para os dois tradutores (em Bishop Eugene/mean e em Zenith wide/Clyde/rhyme). Se eles tivessem mantido o nome que Drummond escolheu, não seria viável manter as rimas dessa estrofe, uma vez que não existem na língua inglesa palavras com a terminação "-undo". Além disso, Zenith, ao optar por "Clyde", estabelece novas relações, como a referência à famosa dupla Bonnie e Clyde, por exemplo, que constitui o imaginário popular dos falantes de língua inglesa, especialmente os americanos. Ambos tradutores, dessa forma, dão novos sentidos à estrofe e parecem valorizar a recepção que o poema terá entre os leitores de língua inglesa. Para Carvalhal (2000), que afirma que hoje é impossível dissociar o processo de tradução do processo de recepção de uma obra, é "suprimindo alguns elementos que seriam desconhecidos ao leitor, introduzindo outros que lhe são familiares, [que] o tradutor facilita sua aceitação, possibilitando uma acolhida mais imediata" (CARVALHAL, 2000, p. 90).

\section{Os ombros suportam o mundo}

O poema Os ombros suportam o mundo está no livro Sentimento do mundo (1940) que, junto ao A rosa do povo (1945), caracteriza um dos momentos em que a poesia de Drummond estava mais socialmente ativa. Os poemas dessa fase são mais longos, densos e, em sua grande maioria, trazem como temática as fissuras que o mundo estava sofrendo em um período marcado por guerras. É nesse sentido que Os ombros suportam o mundo, ao longo de seus vinte e três versos, divididos em quatro estrofes, investiga, em um tom bastante ontológico, o lugar do eu em um "tempo de absoluta depuração".

No título desse poema, há uma metonímia, em que os ombros representam o todo das pessoas que suportam as adversidades de um cotidiano impossível. Na versão de Zenith, há um apagamento dessa metonímia, porém o sentido se mantém próximo de You carry the world on your shoulders, ou seja, "Você carrega o mundo nos seus ombros". Embora haja novamente uma amenização, de "suportar" no original, para "carry" na tradução, fica claro que Zenith 
optou por preservar a métrica, visto que tanto o título de Drummond quanto o de Zenith contêm 8 sílabas poéticas e apresentam o mesmo ritmo $(2,6,8)$. Na tradução de Elizabeth Bishop, o título fica Your shoulders hold up the world, mais próximo do original semanticamente, porém sem preservar nem o número de sílabas poéticas, tampouco o ritmo. É notável, ainda, que ambas traduções optam por personificar esses ombros. Enquanto, no original, Drummond utiliza o artigo definido sem caracterizar uma pessoa específica (os ombros que carregam o mundo poderiam ser quaisquer ombros), Zenith e Bishop especificam (em Zenith você carrega e em Bishop seus ombros).

Há um estranhamento, de forma geral, na dicção das traduções desse poema. Essa sensação de desajuste parece vir do nível de formalidade que varia entre o original e as traduções. Na língua portuguesa brasileira, conseguimos identificar três formas de uso de pronome pessoal na segunda pessoa do singular: o você e o $t u$ conjugados na terceira pessoa do singular, padrão coloquial recorrente na língua falada, sendo o tu mais usado na região sul e nordeste; e o tu conjugado na segunda pessoa do singular, forma mais rara, encontrada mais facilmente na modalidade escrita e que denota um grau de formalidade mais alto. É a esse 122 segundo uso que Drummond recorre, dando ao poema esse tom mais formal:

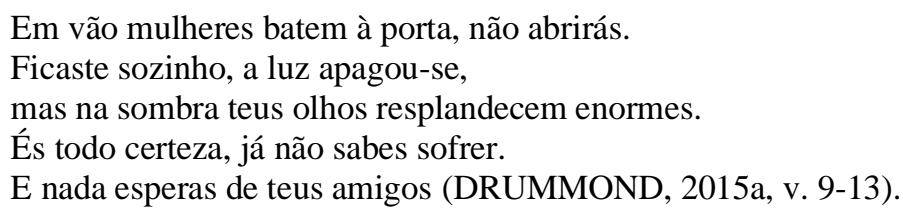

Já na língua inglesa não há esta distinção e o you (você) é o único pronome pessoal de segunda pessoa, sendo assim, a formalidade fica por conta dos outros elementos da frase (escolher um verbo de origem latina no lugar de um phrasal verb, por exemplo). Dessa forma, o tradutor tem que aplicar um esforço muito maior para dar conta de uma formalidade que não consegue ser expressa apenas através da escolha do pronome, como no português:

\footnotetext{
Women knock on your door in vain, you won't open.

You're all alone, the light is out,

but in the darkness your eyes shine enormous.

You're certainty itself, you can no longer suffer.

And you expect nothing from your friends (ZENITH, 2015, v. 8-12)
}

$\mathrm{Na}$ citação acima, podemos observar que Zenith mantém o grau de formalidade na escolha em versos como "but in the darkness your eyes shine enormous", em que "enormous" é a opção mais formal para "enorme", normalmente traduzido para "huge", sinônimo mais 
informal; porém escolhe utilizar as contrações "you're" (você está) e "won 't" (não irá), quando "you are" e "will not" levariam o leitor a identificar muito mais facilmente a linguagem formal do poema.

\section{Considerações finais}

Essa análise procurou dar visibilidade ao diálogo que a tradução estabelece com o original, reconhecer em que medida ela o reproduz e verificar como as características de uma lírica em português estão presentes no lirismo em inglês. Tentamos levantar hipóteses sobre as escolhas de Zenith em seu projeto tradutório, comparando-o com os poemas originais e, quando possível, com traduções já realizadas por Bishop e Nist.

É importante enfatizar que a poesia drummondiana oferece um grau de dificuldade bastante alto a qualquer tradutor, devido especialmente à extensão dessa, já que Drummond publicou mais de 23 livros de poesia. Dessa forma, se torna desafiador para um tradutor ter uma noção do todo ou ter uma compreensão geral da obra de Drummond. Assim, detalhes como a noção de gauche, significativa para a construção da lírica drummondiana, pode não aparecer na tradução, conforme discutido na análise. Ligado a isso, destacamos ainda que o poeta mineiro escreveu durante mais de 50 anos, de forma que suas obras estão inseridas em contextos sóciohistóricos diversos. Sendo assim, o tradutor precisa ser capaz de apreender poesias de diferentes tempos, que variam em tom, abordagem de temáticas e construção de sentido. A multiplicidade das temáticas pode também se apresentar como um fator que aumenta o trabalho de pesquisa do tradutor, que precisa lidar com campos lexicais diversos. Apesar disso, os poemas quase sempre em verso livre (o que não quer dizer que não possuam ritmos sofisticados) e a ocasional ausência de rimas podem vir a atuar como facilitadores da prática tradutória.

A partir dos poemas selecionados da obra Multitudinous heart: selected poems by Carlos Drummond de Andrade (2015), traduzidos por Richard Zenith, depreendemos características singulares no projeto tradutório de Zenith, o qual faz escolhas e encontra soluções tradutórias que ainda não tinham aparecido em traduções anteriores da poesia drummondiana. Assim, o tradutor, que equilibra forma e conteúdo, atualiza a poesia de Drummond em língua inglesa. Em um movimento que se aproxima e que distancia do original, percebemos que as escolhas de Zenith buscam dialogar com o público leitor, bem como preservar o ritmo e as rimas da poesia drummondiana. Em relação ao nível de formalidade das línguas, notamos que o tradutor, frequentemente, não utiliza a mesma abordagem de 
Drummond, o que, em alguns momentos, o afasta de determinada dicção drummondiana, mais pessimista e distante do leitor.

Por fim, é importante ressaltar que o presente trabalho não objetivou esgotar o assunto, muito menos chegar a respostas definitivas. Traçamos acima algumas hipóteses e delimitamos o que pareceram tendências nos poemas analisados, a fim de iniciar o debate sobre essa tradução ainda recente de poemas de Drummond traduzidos para a língua inglesa por Richard Zenith, cientes, entretanto, das lacunas que serão preenchidas em estudos futuros.

\section{REFERÊNCIAS BIBLIOGRÁFICAS}

ANDRADE, Carlos Drummond. Nova reunião: 23 livros de poesia. São Paulo: Companhia das Letras, 2015a.

ANDRADE, Carlos Drummond. Multitudinous heart: Selected poems, a bilingual edition. Traduzido por: Richard Zenith. New York: Farrar, Straus and Giroux, 2015 b.

BENJAMIN, Walter. A tarefa do tradutor de Walter Benjamin: quatro traduções para o português. Belo Horizonte: Fale/UFMG, 2008.

124 BISHOP, Elizabeth. Travelling in the family, selected poems by Carlos Drummond de Andrade. Manchester: Carcanet New Press, 1981.

CAMPOS, Haroldo de. Da tradução como criação e como crítica. In: CAMPOS, Haroldo de. Da transcrição poética e semiótica da operação tradutora. Belo Horizonte: FALE, UFMG, 2011.

CARVALHAL, Tânia. De traduções, tradutores e processos de recepção literária. Revista Brasileira de Literatura Comparada, v. 5, n.5. p. 86-91, 2000. Disponível em: http://revista.abralic.org.br/index.php/revista/article/view/72/73. Acesso em: 20 dez. 2019.

GENETTE, Gérard. Palimpsestos: a literatura de segunda mão. Ed. Bilíngüe (extratos). Traduzido por: Luciene Guimarães e Maria Antônia Ramos Coutinho. Belo Horizonte: FALE/UFMG, 2005.

GLEDSON, John. Influências e impasses: Drummond e alguns contemporâneos. São Paulo: Companhia das letras, 2003.

JUNQUEIRA, Ivan. A poesia é traduzível? Estudos avançados, São Paulo, v. 26, n. 76, p. 914, 2012. Disponível em: http://www.revistas.usp.br/eav/article/view/47533. Acesso em: 20 $\operatorname{dez} 2019$.

MOURA, Murilo. Tédio e segredo: duas formas de recusa nos anos 1930. O Eixo e a Roda, Belo Horizonte, v. 19, n. 1, p. 39-56, 2010. Disponível em: http://www.periodicos.letras.ufmg.br/index.php/o_eixo_ea_roda/article/view/3339/3269. Acesso em: 20 dez. 2019. 
NIST, John. In the middle of the Road, selected poems of Carlos Drummond de Andrade. Tucson: Universitiy of Arizona Press, 1965.

SANT'ANNA, Afonso Romano de. Introdução ao gauche. In: Leituras de Drummond. Caxias do Sul: EDUCS, 2002.

SANTIAGO, Silviano. Introdução à leitura dos poemas de CDA. In: ANDRADE, Carlos Drummond de. Poesia completa. Rio de janeiro: Nova fronteira, 2007.

\footnotetext{
* Mariane Pereira ROCHA - Doutoranda em Letras pela Universidade Federal de Pelotas. Mestre em Letras (2019) pela Universidade Federal de Pelotas. Especialista em Literatura Inglesa (2017) pela Universidade Braz Cubas. Graduada em Letras (2015) pela Universidade Federal do Pampa. Professora no Instituto Federal Sul-RioGrandense (IFSul), campus Jaguarão. Jaguarão, Rio Grande do Sul, Brasil.

Currículo acadêmico: http://lattes.cnpq.br/1196187972677645

ORCID: http://orcid.org/0000-0002-0126-8063

E-mail: marianep.rocha@gmail.com

** Aulus Mandagará MARTINS - Doutor (2002) e Mestre (1993) em Letras pela Universidade Federal do Rio Grande do Sul. Graduado em Letras habilitação Português e Francês (1988) pela Universidade Federal de Pelotas. Realizou estágio pós-doutoral (2018) na Universidade Federal do Rio Grande do Sul e na Universidade Federal de Santa Maria (2010). É professor titular na Universidade Federal de Pelotas. Pelotas, Rio Grande do Sul, Brasil. Currículo acadêmico: http://lattes.cnpq.br/5779140095343632

ORCID: http://orcid.org/0000-0002-0590-1890

E-mail: aulus.mm@gmail.com
} 